\title{
Resistance and Creativity in English Reading Lessons in Hong Kong
}

\author{
Angel Mei Yi Lin \\ (In Language, Culture and Curriculum, vol.12, issue 3, pp. 285-296.)
}

\begin{abstract}
In this paper, I present a fine-grained analysis of a videotaped lesson segment of a Form 2 (Grade 8) English reading lesson in a school located in a working class residential area in Hong Kong. The excerpt was taken from a larger corpus of similar lesson data videotaped in the class over three consecutive weeks. The analysis shows how these limited-English-speaking Cantonese school children subverted an English reading lesson that had a focus on practising skills of factual information extraction from texts and negotiated their own preferred comic-style narratives by artfully making use of the response slots of the IRF (Initiation-Response-Feedback) discourse format used in the lesson. The analysis shows the students' playful and artful verbal practices despite the alienating school reading curriculum which seems to serve to produce an uncritical labour. The implications for teaching are discussed.
\end{abstract}


Crayon Shin-Chan said to his classmate angrily, "Let's have a duel!"

His classmate replied fiercely, "Okay!"

"They are going to fight again! Let's call the teacher!" Another classmate said anxiously and speeded away.

When the teacher came, the two boys were tickling each other with their fingers, each trying hard not to laugh.

"They are using the 'mutual tickling' method to see who's stronger; the one who first laughs loses!" A bystanding classmate explained to the amused teacher.

(Conversations taken and translated from the Crayon Shin-Chan comics series, "Taking flight", Vol. 9, p. 110.)

\section{Sociopolitical Background: Language and Power in Hong Kong}

Hong Kong was a British colony situated on the southern coast of China. Since its cession from China to Great Britain in 1842 as a result of China's defeat in the Opium War, it had changed from an agrarian fishing port to a labour-intensive industrial city in the 1960s and 70s. In the 1980s and 90s, with the boom of China trade following "the open door" policy of China, Hong Kong had gradually changed from a light-industry based, manufacturing economy to an economy primarily based on the re-export of products processed in China, and business and financial servicing for China (Ho, 1994). It also has an increasing demand for a low-level white-collar workforce with some functional skills in English (e.g., shipping, export/import, accounts clerks; receptionists; telephone operators; typists; secretaries). While the universities are producing the bilingual middle-management workforce, the majority of secondary schools are producing the non-management white collar labour for the day-to-day routine work that requires some English. 
Despite its international cosmopolitan appearance Hong Kong is ethnically rather homogeneous. About $98 \%$ of its population is ethnic Chinese, and Cantonese ${ }^{1}$ is the mother tongue of the majority. English native speakers account for not more than $2 \%$ of the entire population. They had constituted the dominant class, at least until July 1997 when the sovereignty of the colony was returned to China and Hong Kong became a Special Administrative Region (SAR) of China.

Notwithstanding its being the mother tongue of only a minority, English has been both the language of power and the language of educational and socioeconomic advancement, i.e., the dominant symbolic resource in the symbolic market (Bourdieu 1982/1991) in Hong Kong. Even after Hong Kong became an SAR of China English has maintained its status as a primary language of higher education and business, partly due to its global domination as a major language of science, technology and business. For instance, it is still the

${ }^{1}$. Cantonese is a regional Chinese language widely spoken in the southern Chinese province of Guangdong. Phonologically it is quite distinct from Modern Standard Chinese (the national standard language of China, known as "Mandarin" or "Putonghua"); however, there are both overlaps and differences in the grammar and lexis of the two codes. While linguists and educationists differentiate between Cantonese and Modern Standard Chinese as two distinct codes, Hong Kong Chinese people in their daily life often refer to their own language as "jung-man", meaning "Chinese language". It is usually the linguist who sees Hong Kong Chinese as in fact speaking Cantonese as their mother tongue and reading and writing a form of Modern Standard Chinese that has been influenced by Cantonese lexis and syntax. Hong Kong Chinese themselves however usually do not pay attention to these distinctions in their daily language practices. They know that the written style is and should be different from the spoken style of their language, but they consider themselves using "jung-man" all the same. They can distinguish spoken Mandarin or Putonghua from Cantonese but they see them as different regional ways of speaking "jung-man" and generally do not see them as constituting totally different languages. Ethnically and culturally they regard themselves as Chinese and "jung-man" as their familiar native language in contrast to English, which they do not ordinarily speak among themselves and which they largely see as a language of the "gwai-lou" (a Cantonese slang word referring to Westerners) or the middle- class yuppies, who tend to code-mix or code-switch between Cantonese and English. 
medium of instruction of most universities and an important language requirement of most white-collar, professional, executive and civil service jobs. While Putonghua (Mandarin Chinese, the standard national language of China) is rising in its political importance, it seems unlikely that it will take over the socioeconomic and higher education functions of English in the near future.

The symbolic market is embodied and enacted in the many key situations (e.g., educational settings, job settings) in which symbolic resources (e.g., certain types of linguistic skills,

cultural knowledge, specialized knowledge and skills, etc.) are demanded of social actors if they want to gain access to valuable social, educational and eventually material resources (ibid.). For instance, a Hong Kong student must have adequate English resources, in addition to subject matter knowledge and skills, to enter and succeed in the English-medium professional training programmes of medicine, architecture, legal studies, etc. in order to earn the English-accredited credentials to enter these high-income professions. The symbolic market is therefore not a metaphor, but one with transactions that have material, socioeconomic consequences for people.

\section{The Schooling and Examination Systems: Institutions of Social Selection}

The schooling system can be said to be largely subsumed under the public examination system, a major institution of social selection (Bourdieu \& Passeron, 1977) in Hong Kong. The secondary school curriculum is, for instance, in reality, if not in name, heavily influenced by the public examination syllabuses. Public examinations are important because the job market uses public exam results as an important screening criterion on job applicants. A student's higher and professional education opportunities are also dependent on her/his public examination results. Schools in turn depend on its graduates' public examination results to acquire prestige and status among parents and in the community. Teachers are therefore under school administrators' constant pressure and monitoring to 
produce good public examination results in the students. It is not difficult for a success-oriented student to discover that public exam-taking skills constitute the most important factor for success in school and in the society (at least initially) and that the rule of the game does not hinge on gaining "education" or "learning" but exam-taking skills².

\section{The Larger Study: Uncovering Institutions of Social Reproduction}

The data and analysis reported in this chapter have been taken from a larger study (Lin 1996a) which examined how English lessons were organized in junior forms (Form 1-3; comparable to Grade 7-9 in North America) in secondary schools in Hong Kong. The purpose of the study was to find out whether schools situated in different socioeconomic contexts provide their Cantonese-speaking students with differential access to the socioeconomically dominant English linguistic and cultural resources in Hong Kong, and thus serve as institutions of social reproduction (e.g., perpetuating/reproducing the lack of linguistic and cultural capital for success among socioeconomically disadvantaged children).

In the study, I visited and videotaped all the English lessons on at least five consecutive school days in each of the eight English classes of the eight teachers participating in this study. The eight teachers were in seven schools from a range of socioeconomic and academic backgrounds. I informally interviewed small groups of the students, and collected other curricular, assessment, and background information on the classes and the schools. The data excerpt included in this chapter has been taken from a corpus of lesson data videotaped in the class of one teacher $(\mathrm{Mr} . \mathrm{Chan})^{3}$ over three consecutive weeks.

\footnotetext{
${ }^{2}$. For instance, many students are willing to pay expensive tuition fees to private exam-oriented tutorial centres to get tips and training on exam-taking skills. ${ }^{3}$. All personal names are pseudo-names.
} 


\section{Mr. Chan and his Class:}

Mr. Chan's class consisted of thirty-nine students, nineteen male and twenty female, aged between thirteen to fourteen. The school is located in a town close to an industrial area. The students in the class largely came from families who lived in the nearby public housing estates. Their parents were largely manual workers and their education level ranged from primary school to junior secondary school. They spoke only Cantonese at home and most of the boys loved to read comic strips (translated from Japanese into colloquial Chinese which is close to Cantonese in style). They did not read any English apart from school textbooks. Their English fluency, as can be seen from how and what they spoke in the classroom, seemed to be rather limited for their grade level. There were many words in the text that they did not understand or did not know how to pronounce.

Mr. Chan appeared in every way to be a caring and responsible teacher. He was however at a disadvantage in his teaching of this class due to his level of English fluency. However, I must point out that this is by no means an "individual" fault of the teacher. The English language teaching courses he took in the two-year part-time Postgraduate Certificate of Education Programme at the university do not seem to be designed to provide non-English majors with the necessary access to English linguistic resources, e.g., no fluency development component in the programme. It also appeared to be a language he used primarily in the school context, with little overlap with his life outside of school. For example, his own leisure activities, like those of many people in Hong Kong, did not require much use of English.

\section{Mr. Chan's Reading Lessons}


The overall organization of Mr. Chan's reading lessons can be outlined in terms of the following sequence of phases:

\section{(i) The pre-reading phase:}

This phase can be further divided into the warm-up questioning phase and the reading-questions introduction phase:

\section{(a ) The warm-up questioning phase:}

The teacher starts the reading lesson by asking students some pre-reading questions which are generally related to the topic of the text and elicit students' personal experience and knowledge about the topic. This is a standard procedure recommended by most L2 reading teaching methodologies (e.g., Barnett 1989). According to these teaching methods, the aim of this pre-reading, warm-up procedure is to arouse students' interest and motivation to read the text, and to activate the relevant background knowledge schemata that will facilitate the students' comprehension of the text.

(b) The reading-questions introduction phase:

After asking some pre-reading questions, the teacher typically begins to introduce comprehension questions that are specifically related to the content of the text. However, no answers are expected at this stage, the students are asked to find answers to these questions from the text. Again, this is a typical procedure recommended by $\mathrm{L} 2$ reading methodologies, which advise teachers to help students to become focused readers by providing them with a purpose to read and an advanced organizer to guide their reading comprehension.

(ii) The reading phase: 
After students are introduced to the comprehension questions, they are instructed to read the text to find out the answers to the set of questions just introduced. The teacher assigns a period of time in which students are to do their silent reading and to "mark" the answers to the questions on the text.

(iii) The question-and-answer phase:

Typically, the teacher begins to ask the comprehension questions and elicit answers from students only after the silent reading period, i.e., after students are supposed to have finished reading the whole text and have marked the answers to the set of comprehension questions with a pencil. The lesson segment we shall examine in this chapter is taken from the question-and-answer phase, in which the dominant discourse format used is the IRF (Initiation-Response-Feedback) format (Sinclair \& Coulthard 1975, Mehan 1979, Heap $1985,1988)$.

The organization of Mr. Chan's reading lessons shows that the purpose of reading, as formulated by the teacher, seems to be one of marking the answers to the given questions in the storybook, and then to give these answers to the teacher, who is going to elicit them from the students after the students have spent some time working on their own. The teacher seems to formulate reading as merely extracting from a text answers (or information) to a pre-given set of factual questions (see Table 1 below). More creative, non-factual (or non-information type) questions such as: "Do you like the story? Which character do you like the best? If you were Tin Hau, what would you..." have not found their way into the reading lessons, and "reading" in the classroom (even when one is not reading informational, expository types of materials) bears a striking resemblance to "reading" in the examination hall. In the following section, we shall look in more detail how the teacher's organization of the reading phase and question-and-answer phase seems to be geared towards doing information-extraction from texts, and how some students 
negotiate their own story by taking advantage of the response slot of the IRF discourse format.

INSERT TABLE 1 HERE

\section{Teacher's Text Information Extraction Practices vs. Students' Negotiation of an Alternative Story}

In Mr. Chan's lesson, there is a clear division between the reading phase and the question-and-answer phase. We shall discuss each of them below:

\section{(i) The reading phase:}

In this phase, the students are expected to do their reading silently and individually and as they read they are expected to mark answers in the text to a pre-given set of questions. They have not been encouraged to discuss or check with each other their answers. In fact, they are supposed to do this on their own quietly, i.e., not to "talk with your neighbours"; there is evidence in the transcript of the teacher asking the students to keep quiet and focus on their work and not to talk to their neighbours, e.g., a girl appears to have finished very quickly and begins to fiddle around; the teacher asks her to keep quiet and expresses doubts about whether she has "really" finished her work; she responds by saying that the questions are "Gum gaan-daan!" (i.e. "so simple") that she has got them done already. This incident seems to reflect the student's perception of "reading": one is counted as having finished reading a text as soon as one has finished answering the pre-set questions for the text. It seems the idea never enters their minds that written texts can be something to enjoy, to read and re-read, to analyse literarily, to respond to creatively and personally... etc. Once you 
have answered the pre-set questions, you are done with the text and done with "reading". Besides, the student's own way of responding to and interacting with the text has been pre-defined and pre-constrained by the pre-given set of factual questions.

\section{(ii) The question-and-answer phase:}

After ten minutes, Mr. Chan begins to engage the students in a "certified-lesson-knowledge-corpus co-production process", through the use of an I (L2-L1) - R (L1) - F (L1-L2) format (Lin 1996b), in very much the same way it has been used in the pre-reading phase. However, in this phase the questions to be asked by the teacher in the initiation slots are already known and given, and the answers to be provided by the students in the response slots are also supposed to be pre-formulated (or pre-marked-out in the storybook). So, it is not so much a discussion or "talking about" the storybook as it is "checking answers" to the pre-set questions, which is a recurrent practice in other lessons of this class as well (not included in this analysis) (e.g., checking answers to grammar exercises, vocabulary exercises..., etc.).

Let us look at the following example, taken from the beginning of the question-and-answer phase:

Example 1: (See Appendix for notes on transcription)

608.8 T: Alright (1) let's (1) look at the story, Tin Hau, Queen of Heaven. (3) Look at the first paragraph, "Before Tin Hau became the Queen of Heaven, and Goddess of the Sea (1) she: lived (1) a mortal life as a merchant's daughter, named ... Lin Mo (1) Lin Moniang" right?=

707.1 S: =Linmoniang $=\{$ voice soft on the tape $\}$

707.3 T: =so ... look at the first question, (2) what was the name of Tin Hau before she became the Queen of Heaven?=

709.5 Chan: =Lahm-Mahk-Neuhng <Linmoniang $>$ != 709.8 T: Yeh ... that answer's.. so easy, (2) (Lahm).. Lin Moniang, right?= 
711.5 S: =Linmoniang! $\{$ spoken in a joking intonation $\}$

712 T: Number two ... what kind of work did.. her father, and brothers do?

713.5 S1: (Dim duhk aa <How to read it>?)

713.8 S2: m-e-r-c-h-(? ?)

714.1 T: Now.. who knows the answer? (2.5) r'ai? (6) let me ask question, (1.5) aah: (1)

Wohng-Ji-Jung (3) number 2 (2) haa? (3) Wohng-Ji-Jung

$720.5 \mathrm{~W}:$ Eh... =

720.8 T: =What do they do?

$721 \mathrm{~W}:($ Fishing $)=$

721.2 T: =Fishing? (1) they are fishermen? (1.5) Is it correct? (2) Haih maih yyuh-fu leih gaa heui.. deih <Are they fishermen>?

723.3 Chan: Oh mh-haih aahk <Oh, no $>$ !

723.8 T: Heui-deih jouh me-yeh gaa $<$ What do they do $>$ ?=

724 Chan: jouh seung-syuhn ge $<$ do merchant ships $>$ !

724.5 T: Right, where can you find the .. answer? (1) =

725 S: (s-a-i-1 ? ? sail)

725.5 Chan: Line three!

725.7 =T: (aahk) merchants- aahk..heui haih sheung-yahn leih go wo <they are merchants $>$ !

Look at second paragraph, (1) Lin ..... (090)

The teacher starts off by suggesting that they will look at the story and then he reads out the title of the story (turn [608.8]). Then he draws his students' attention to a specific paragraph in the story and reads out the relevant part from which the answer to Question 1 can be found (turn [608.8]). It is only after reading out this part that he starts to ask the first question (turn [707.3]). His orientation to specific parts of the text as the basis for the answers to the set of questions is thus demonstratively clear right from the beginning.

A student shouts out an answer, "Lahm-Mahk-Neuhng", which is a Cantonese rendering of the name of Tin Hau before she became Heaven-Queen. It is interesting to notice how the teacher acknowledges it: he says "Yeh.. that answer's .. so easy, ... (Lahm).. Lin Moniang, right?" (turn [709.8]). He is almost to reiterate the name in Cantonese ("Lahm"), but then he corrects himself and renders the name in English, i.e., in the Anglicized form that is rendered in the English storybook. This confirms with our observation above that the Feedback has to contain a reformulation of L1 answers (offered by students) in L2 as it is only the latter that is to count as part of the certified lesson-corpus co-constructed. 
Then he goes on to ask, "Number two..." (turn [712]). This is interesting: he prefaces his question with the "number" of the question like going through a list. This is a typical "question-opener" in the "checking answers" discourse format that is recurrent in other lessons of this teacher as well (not included in this analysis).

Rejecting an entirely reasonable but not text-based answer, he reinitiates again in L1, and this time receiving an answer from a girl (Chan), who interestingly paraphrases and summarizes the relevant English part of the storybook ("... merchant's daughter... father and brothers often sailed across the sea to buy and sell goods") in a concise and idiomatic Cantonese phrase, "jouh seung-syuhn" (turn [724]) ("do merchant ships"--this is odd in English, but the meaning and lexical structure of the Cantonese phrase is entirely acceptable and idiomatic in the Cantonese language). We see that this Cantonese construction offered by her as a response to the teacher shows remarkable sensitivity to the linguistic structure of the teacher's L1 question, "Heuideih jouh me-yeh gaa?" ("What do they do?") (turn [723.8]) (again, in Cantonese, this is idiomatic and is taken to mean "What they do for as a job?").

In other words, the student's L1 response seems to be a result of a great sensitivity to the teacher's question, and not necessarily reflecting the lack of English linguistic resources to answer in English on her part. This would have implications for the teacher's language use patterns, if the teacher wants to maximize the opportunities for students to use English in the language classroom.

On the other hand, the teacher highlights the need to base one's answer on relevant parts in the text by asking the student where she can find the the answer (turn [724.5]). And this time, he asks this in English (probably this switch back to English signals an imminent need to turn to the English text), and the girl answers him in English, too (turn [725.5]).

The need to base one's answer (or to "find the answer") in the text is a recurrent concern of the teacher voiced in his recurrent prompts and follow-up questions such as "Where can you find it?", "Does the book really say so?", "Look at paragraph __, line ___, etc.. (found in other parts of the transcript). However, there are times when a bookish answer is so boring, especially when these students feel that this story of the Chinese Heaven-Queen is so familiarly boring! (some evidence of this in other parts of the transcript). And the factual nature of the set of questions has left so little room for imagination for these lively thirteen-year-olds. In the following example, we find the creativity of the children bursting 
out in a niche that they exploit and capitalize on in an otherwise probably uninteresting IRF discourse:

\section{Example 2:}

870 T: Yauh mat-yeh faat-sang aa <What happened>? .. Leih-Lohn-Minng (2) dong heui- daap heui maa-mih <when she answered her mum> (1) heui maa-mih aai heui meng ne heui daap heui go sih-houh yauh mat-yeh faat-sang aa <her mum called her name, and when she answered her mum, what happened $>$ ?

*872 Leih: Heui louh-dauh dik-jo lohk (deih) <Her old-man fell off to the (ground)>. \{ chuckling towards the end of his sentence $\}=$

872.5 Ss: =Haha! haha! haha! hahahaha! \{other Ss laughing hilariously\}

872.8 T: Me aa?! (2) daaih-seng di <louder>! \{against a background of Ss' laughter \}

*873.2 Chan: Heui louh-dauh dik-jo lohk gaai woh <Her old-man fell off to the street>! \{ chuckling) $=$

873.5 S1: =Hihihihik!!= $\{$ laughing $\}$

873.8 S2: =(Go douh) yauh gaai gaa $\mathrm{me}<$ (Is there) a street $>$ ?

*874 T: Go douh yauh gaai me <Is there a street>? $\{\mathrm{T}$ in an amused tone; some students laugh $\}$

*874.5 L: Dik-jo lohk // hoi <fell into the sea>=

*874.8 //T: =Dik-jo lohk bin-douh aa:: <Where did he fall into $>$ ? quite amusingly\}

875 L: Hoi aa $<$ Sea that is $>$.

875.2 T: Haahk.. dik-jo lohk hoi <Yes.. fell into the sea>. 875.5 S1: Dik-jo lohk gaai hahaha <fell off to the street>

875.8 S2: Heui louh-dauh dik-jo lohk gaai aa <Her old-man fell off to the street>.

876 T: // Right? (1) Her father dropped into the SEA!==

876 //S3: Hekhek! \{laughing\}

$876.5==$ T: Right? (2) gum-yeung sei-jo laak <in that manner died>... SHH! (1) hou-laak $<$ okay $>$.. jeui-hauh laak < finally $>$.. SHH! number ten ... 
The question (turn [870]) has been asked in English earlier, but no student response has been forthcoming, and the teacher is asking it again in Cantonese, and also specifically directs it to a student (Leih-Lohn-Mihng), ensuring that someone is going to answer it. Now, something interesting happens. Leih says something (turn [872]; the Cantonese word "louh-dauh" literally means "old-bean" and is a common colloquial, not very respectful word for "father") which rouses other students to hilarious laughter (turn $[872.5])$.

The student has exploited the Response slot to do something playful, to slip in a contribution that will turn the whole story into a comic-strip type of story, which they so enjoy reading outside the classroom (based on what they told me when I chatted with them after school, and on their responses to questions about the kinds of extra-curricular reading they do in a questionnaire I gave them). In their most favourite comic strips (which have been translated into Cantonese-style-Chinese from Japanese), the characters usually do funny, impossible things, e.g., a boy changes into a girl when he falls into cold water and changes back to a boy when he's showered with hot water; or, the father of the boy changes into a big black bear when coming into contact with hot water, etc.., and amusement and enjoyment come from the superimposing of impossible and unpredictable fantasy with the familiar, predictable, and boring mundane world. It seems that the boy who provides this funny answer (turns [872], [873.2]) is a skillful story-teller with a ready audience, and this is reflected in the overwhelmingly positive response from his fellow students (i.e., their hilarious laughter, showing their great amusement derived from this twist of the story effected by his answer: her father fell off into the street (from a merchant ship amidst a stormy ocean)! His change in the plot will make a very funny and imaginative comic-strip type story. 
The teacher cannot hide his amusement himself (turns [874], [874.8]) but insists on the text as the authoritative basis for answers to the question. He challenges, "Go douh yauh gaai me?" (Is there a street?) (turn [874]), and goes on to demand that the student give him a text-based answer, which he can acknowledge, reformulate into English, affirm and certify (turn [876]). Throughout the teacher has been demonstrating to his students that reading means finding answers to pre-given questions in the text; and there is little more you can do or play around with while reading a text. 


\section{What Counts as Literacy? And Literacy for What Purposes?}

The organization of Mr. Chan's reading lesson is not an isolated example. Similar examples can be found in other classes in my larger corpus of classroom data (Lin 1996a). The point of English reading lessons in Hong Kong schools seems to be primarily one of practice in extracting prescribed information from texts. This seems to have followed naturally from the pragmatic emphasis of the school English curriculum and the way English reading comprehension is assessed in public examinations. English seems to be conceived as mainly for academic and job-related purposes in Hong Kong. The information-extraction approach to reading seems to dominate most English reading practices in school, even when the texts being read are stories and not a type of technical, academic or job-related manuals which might more typically require information extraction in many contexts. The schools thus seem to serve as training grounds to churn out graduates skilled in extracting specific information from English texts to accomplish prescribed tasks.

School children, however, might seize whatever opportunities they can find in the classroom to negotiate their own sense of the text, for instance, text not as an information-holder, but as a source of enjoyment. When the prescribed school text proves to be unimaginative or unengaging, they exercise their own creativity to recreate a new plot, to negotiate a comic type of story, which suits their taste. It seems that they are negotiating their own kind of literacy for their own purposes, in spite of the illegitimacy of their own literacy and their own purposes in the school context. 


\section{Coda: Rethinking Teacher's Role}

In this concluding section, an alternative model of literacy is proposed that emphasizes affirming and capitalizing on what children bring to the classroom: their indigenous linguistic, discourse, and cultural resources.

Analysis of students' classroom practices shows that the students' artful story co-construction practice can be a potential resource in the English lesson if the teacher can harness and build on it. While one might simply dismiss the students' discourse practice exemplified above as an instance of student uncooperative behaviour, one might also take a very different approach to it: there is the possibility of capitalizing on this kind of popular story-telling resource of the students in a writing programme, for instance, by allowing students a chance to co-construct/retell/rewrite the story that they have read in the textbook. More research and curricular development are needed in this direction if we see L2 literacy education not as the training of students in the uncritical, factual extraction of information from texts, as is expected of low-level white-collar workers in the workplace (see Section 1 above).

The critical teacher thus needs to reflect on her/his role: does s/he really want to play the role of producing uncritical students for examination and uncritical labour for the workplace? Or, does s/he want to foster in students a critical attitude towards texts, the curriculum, and their own socioeconomic positioning in the society? While there is no denying that the teacher needs to prepare students for examination which emphasizes literacy as uncritical information extraction, the teacher can perhaps discuss various perspectives on reading with students, and in this way, work with students towards a critical understanding of the curriculum and how they can widen their own repertoire of literacy skills beyond those prescribed by the curriculum, without negating or excluding their creative linguistic and sociocultural resources from the classroom. Teachers in 
working class schools can choose to serve as part of the society's machinery in stratifying and reproducing labour to fill low-paying jobs, or to work with students towards uncovering their creative potential and towards a critical exploration of the kinds of literacy they can achieve beyond those prescribed by the curriculum and the examination syllabus. We need more work in exploring feasible alternative classroom practices. As things stand now we are a long way from reaching this objective. It is, however, my hope that this paper might arouse some discussion that can lead to future efforts in this direction. It is with this modest aim that this paper has been written.

\section{References}

Barnett, M. V. 1989, More Than Meets the Eye: Foreign Language Reading: Theory and Practice, Prentice Hall, New Jersey.

Bourdieu, P. 1982/1991, Language and Symbolic Power (G. Raymond \& M. Adamson, Trans.), Cambridge University Press, Cambridge, Mass. (Original work published 1982)

Bourdieu, P., \& Passeron, J.-C. (1977). Reproduction in education, society and culture (R. Nice, Trans.). London: Sage.

Heap, J. L. 1985, 'Discourse in the production of classroom knowledge: Reading lessons', Curriculum Inquiry, vol. 15, no. 3, pp. 245-279.

Heap, J. L. 1988, 'On task in classroom discourse', Linguistics and Education, vol. 1, pp. 177-198.

Ho, H. C. Y. 1994, 'The state of the economy', in The Other Hong Kong Report: 1993, ed. P. K. Choi \& L. S. Ho, The Chinese University Press, Hong Kong, pp. 75-94.

Lin, A. M. Y. 1996a, Doing-English-lessons in secondary schools in Hong Kong: A sociocultural and discourse analytic study, Doctoral Dissertation, University of Toronto. 
Lin, A. M. Y. 1996b, `Bilingualism or linguistic segregation? Symbolic domination, resistance, and code-switching in Hong Kong schools', Linguistics and Education, vol. 8, no. 1, pp. 49-84.

Mehan, H. 1979, Learning Lessons: Social Organization in the Classroom, Harvard University Press, Cambridge, Mass.

Sinclair, J. M. \& Coulthard, R. M. 1975, Towards an Analysis of Discourse: The English Used by Teachers and Pupils, Oxford University Press, London.

Usui, Y. 1992/1996, Crayon Shin-Chan Comics Series, vol. 9 [Chinese Edition, 1996], Tong Li Hong Kong Publishing Co., Hong Kong. 
Table 1: The list of comprehension questions the teacher wrote on the blackboard at the beginning of the reading lesson:

1. What was the name of Tin Hau before she became the Queen of Heaven?

2. What kind of work did her father and brothers do?

3. What did she do if they were in danger?

4. What did her mother always worry about her menfolk? ${ }^{4}$

5. Why did Lin suddenly stop speaking?

6. What did Lin see in her vision?

7. How did she save them?

8. Why did her mother cry?

9. What happened when Lin answered her mother?

10. What did Lin become at the end of the story?

${ }^{4}$. There is a grammatical mistake in this sentence. This sentence seems to have been influenced by the teacher's Cantonese. In Cantonese, it is grammatical to say "Her mother worries about them what?". 


\section{APPENDIX: NOTES ON TRANSCRIPTION}

(1) English is transcribed orthographically and Cantonese is transcribed in the Yale system. English translations of Cantonese utterances are placed in pointed brackets $<>$ following the Cantonese utterances. The English utterances, Cantonese utterances, and the English translations are each written in a different font type.

(2) The numerals preceding each turn is the transcribing machine counter no.; a speaking turn is referred to as: turn [counter no.]

(3) "T" represents "Teacher"; "S": Student; "Ss": Students; "Boy" or "Girl" stands for any male or female student voice picked up by the tape and whose identity not available. Words like "Girl 1", "Girl 2", "Boy 1", "Boy 2", "S1", "S2", etc. are used to differentiate between two different boys/girls/students speaking one after the other. The same words may be used at other points in the transcript to differentiate between another two students speaking, but that does not indicate that they are the same two students who have spoken earlier.

(4) Pauses and gaps: A short pause is indicated by ".." and a longer one by "...". Pauses longer than 0.5 second are indicated by the number of seconds in brackets, e.g., (2) indicates a pause of 2 seconds. Gaps between speaking turns are indicated by: ((no. of seconds)), e.g., ((5)) indicates a gap of 5 seconds.

(5) Simultaneous utterances: The point at which another utterance joins an ongoing one is indicated by the insertion of two slashes in the ongoing turn. The second speaker and her/his utterance(s) are placed below the ongoing turn and are preceded by two slashes, e.g.:

017.8 T: //Sheung-hok-kei <Last term> \{spoken in an Anglicized tone $\}$ no, haha! $\{\mathrm{T}$ sounds amused $\}$

017.8 //Boy 3: Mat-yeh giu jouh sports day aa $<$ What is a sports day $>$ ?

If the first ongoing turn is very long, the second utterance is placed under the line of the ongoing turn where the point of intersection appears, e.g.:

508.5 T: Mh-hm mh-hm \{clearing his throat $\}$ (3) mh-hm alright \{all students are quiet now (2) today we'll talk about unit 3, (2) open your book (2) story//book (1.5) who don't have the storybook, ==

510.5 //Boy: storybook

$511==\mathrm{T}$ : raise up your hand (4.5), I want to make sure everybody can read the story, right you two share- share the book. (2.5) How about you? (3) Take out the book. (3 sec) Right you two share the book (3.5) Jeung-Yiuh-Jung.. yeh aah. (5) Right unit three, Tin Hau, Queen of Heaven.= 
(6) Contiguous utterances: Two equal signs $==$ are used to connect different parts of a speaker's utterance when those parts constitute a continuous flow of speech that has been carried over to another line, by transcript design, to accommodate an intervening interruption; see example under (5) above.

The latching of a second speaking turn to a preceding one is indicated by a single equal sign, "=", e.g.:

517 Boy: (Bin yau ying-man ge?) < (How come there's English?) $>=$ $517.3=\mathrm{T}:$ Shh: do you know .. Tin Hau?

(7) Contextual information: Significant contextual information is given in curly brackets: e.g., $\{$ Ss laugh $\}$

(8) Accentuation: Accentuated syllables are marked by capitalization. Lengthening of sounds is marked by colons: e.g. SHOU::LD

(9) Transcriptionist doubt: Unintelligible items or items in doubt are indicated by question marks in parentheses or the words in doubt in parentheses, e.g.:

517 Boy: (Bin yau ying-man ge?) < (How come there's English?) >

524 Girl 1: Ngoh faan ( ? ? ) < r returned (? ? )>

(10) Underlined words in the utterances are words read out from a text.

(11) All personal names are pseudo-names. Names spoken in Cantonese are substituted by a Cantonese pseudo-name, e.g., Chahn-Ji-Mahn; names spoken in English are substituted by an English pseudo-name, e.g., Robert. Original names of places close to the schools are substituted by other place names.

(12) Asterisks (*) are used to indicate turns of particular analytical interest.

$($ Text + refs. + table + appendix: Approximately 5,000 words $)$ 